\title{
The Effects of Instructional Strategies on Preservice Teachers' Math Anxiety and Achievement
}

\author{
Janelle K. Lorenzen \\ Southeastern Louisiana University, USA \\ Thomas J. Lipscomb \\ The University of Southern Mississippi, USA
}

\begin{abstract}
The results reported herein represent the quantitative portion of a mixed method investigation that employed a non-equivalent control group design conducted to determine the effects of teaching methods on math anxiety and achievement among preservice elementary teachers enrolled in a mathematics course. Two teaching methods, inquiry-based learning (IBL) and direct instruction (DI), were compared. These results indicated that math anxiety decreased significantly for the IBL group while increasing for the DI group over the course of an academic semester. There was no difference in measured learning outcomes between the two groups. A significant negative correlation between math anxiety and student achievement, however, was found. Qualitative results, discussed in a companion article, contextualize these findings and reveal that the participants attributed varying levels of math anxiety to several factors including course content, teaching methods, assessments, and student behaviors.
\end{abstract}

Keywords: Math anxiety; Achievement; Preservice teachers; Inquiry-based learning, Direct instruction; Mathematics Education

\section{Introduction}

\section{Theoretical Framework}

Traditional teaching methods, such as direct instruction (DI), have been used in mathematics instruction for decades. These methods, commonly used in elementary, secondary, and post-secondary math instruction, typically involve demonstration and have theoretical foundations in social learning theory (Bandura, 1977). In classrooms in which DI is employed, it is typical for teachers to guide students through mathematical concepts by lecturing while students passively take notes. Following lectures, students may engage in problem-solving activities related to the content just presented (Ardeleanu, 2019). Emphasis is often placed on procedural fluency of mathematical algorithms through repeated practice (Brahier, 2013). This is the type of teaching that many preservice teachers experienced in their elementary mathematics coursework, and thus influenced their beliefs that DI constitutes effective mathematics teaching (Althauser, 2018). This orientation is in contradistinction to recommendations of the National Council of Teachers of Mathematics (NCTM), an organization which has been advocating for mathematics teaching reform for decades (NCTM, 1991).

Another teaching method sometimes utilized in mathematics instruction is inquiry-based learning (IBL), a student-centered, active-learning approach based on the constructivist perspective (Prince \& Felder, 2006). IBL encourages active participation on the part of the learner, geared toward the discovery of new knowledge (de Jong \& van Joolingen, 1998). In an IBL classroom, the instructor acts as a facilitator by actively engaging students in the problem-solving 
process. While characteristics of IBL classrooms vary, features often found include self-discovery of mathematical content, minimal lectures if any at all, emphasis on communication among students and the instructor, alternative assessments, and students' presentations of problems (Schinck, 2014). As Freeman et al. (2014) put it, such an active learning approach "engages students in the process of learning through activities and/or discussion in class, as opposed to passively listening to an expert. It emphasizes higher-order thinking and often involves group work" (p. 8413-8414).

\section{Teaching Methods}

Even though traditional teaching methods are commonplace in mathematics classrooms, these methods may result in students who seldom inquire in the classroom, engage in reasoning or sense-making, or think of themselves as problem solvers (Boaler, 2008). On the other hand, teaching methods promoting active learning may facilitate student success by reducing the number of students who fail or withdraw from a course; result in higher learning gains, particularly for low-achieving students; and improve students' understanding of and selfconfidence in doing mathematics (Freeman et al., 2014; Kogan \& Laursen, 2013; Laursen \& Hassi, 2012; Smith et al., 2009). Benefits of IBL teaching methods with pre-service elementary education students include significant gains in students' mathematical knowledge specific to teaching, deeper understanding of mathematical concepts, and increased self-confidence in teaching ability (Laursen \& Hassi, 2012; Smith et al., 2009).

The Association of Mathematics Teacher Educators (AMTE) and the Conference Board of Mathematical
Sciences (CBMS) recommend a student-centered approach to content courses for preservice teachers. In Standards for Preparing Teachers of Mathematics, AMTE clearly states that quality instruction includes conceptual emphasis on relevant school mathematics, process standards, productive dispositions, and the "instructor use of active-learning and inquiry-based strategies" (AMTE, 2017, p. 154). The CBMS suggests that courses should encourage preservice teachers to develop the habits of mathematical thinking and problem solving, such as reasoning quantitatively and abstractly, explaining and modeling mathematics, being precise in their computations, and constructing valid arguments. The teaching style should be flexible, nurturing, and interactive with plenty of opportunities for preservice teachers to feel successful in solving challenging problems (CBMS, 2012). Features of mathematics content courses that promote high-quality instruction include having preservice teachers reflect upon their own learning as students, providing opportunities for students to use mathematics in a variety of contexts, emphasizing conceptual understanding and reasoning, encouraging students to work collaboratively, and making connections between mathematical content knowledge and pedagogical content knowledge (Lubinski \& Otto, 2004; Mestre \& Cocking, 2002; Thanheiser et al., 2010).

\section{Mathematics Anxiety}

The experience of anxiety is well-known to be counterproductive to content mastery. Further, there is evidence to suggest that preservice elementary teachers may experience the highest level of mathematics anxiety of any college major and female students with low mathematics self-efficacy typically have high levels of mathematics anxiety (Hembree, 
1990; Rozgonjuk, D. et al., 2020). Mathematics anxiety can be defined as a state of discomfort that one experiences when involved in situations requiring the use of mathematics and can affect people of all ages from elementary school children to adults (Ashcraft, 1995; Cemen, 1987; Wu et al., 2014). Many who suffer from mathematics anxiety perceive mathematical tasks as being threatening to their selfesteem and may experience concomitant physical changes such as tension, sweaty palms, difficulty breathing, and inability to concentrate (Burns, 1998; Bursal \& Paznokas, 2006; Dutton \& Dutton, 1991; Hembree, 1990; Trujillo \& Hadfield, 1999). Mathematics anxiety can also negatively impact a student's ability to reason flexibly and creatively about mathematical algorithms and strategies (Fetterly, 2020; Ronghuan et al., 2021).

Preservice elementary teachers have reported that their mathematics anxiety was caused by several factors including having to complete timed tests, mathematics classes being boring, course material being taught too quickly, and a heavy emphasis placed on obtaining the correct answer. All of these are characteristics often found in classes focused on utilizing traditional teaching methods (Harper \& Daane, 1998). Other factors influencing the mathematics anxiety level of college students can be attributed to course instructors not explaining the material well, a heavy reliance on worksheets, and negative teacher dispositions (Rhoads, 2020). It might be hypothesized, therefore, that learner-centered teaching methods that avoided these anxiety triggers might be most beneficial in reducing anxiety experienced and increasing student learning outcomes.
It is possible then that preservice teachers who experience high levels of anxiety are prone to become schoolteachers who continue to experience some level of mathematics anxiety. Students with mathematicsanxious teachers are likely to experience relatively poor mathematics instruction that focuses on algorithmic procedures, insufficient time spent on mathematics in the classroom, and the development of math anxiety themselves (Buhlman \& Young, 1982; Karp, 1988, 1991; Middleton \& Spanias, 1999; Scholfield, 1981). Furthermore, higher mathematics anxiety levels in teachers result in lower mathematics achievement in elementary students (Ramirez, 2018; Szczygiel, 2020). Perhaps if mathematics content courses for preservice teachers emphasized conceptual understanding and inquiry, the cycle of math anxiety being passed from teacher to student could be broken as teaching candidates strengthen their conceptual mathematical understanding.

\section{Research Design}

Although previous research has demonstrated that an active learning approach can be more effective than traditional teaching methods, no study to date has directly compared the efficacy of IBL and DI instruction on either content mastery or mathematicsrelated anxiety within the preservice mathematics classroom. Such were the purposes of the present study. This study specifically addressed how these differing teaching methods might directly affect preservice elementary teachers' levels of mathematics anxiety and achievement in a mathematics content course and provided context by including descriptions of their experiences in the course in relation to their mathematics anxiety and achievement. The general goal of this project was to determine if teaching methods that employ IBL are more effective than DI 
at reducing preservice elementary teachers' levels of math anxiety while increasing their achievement.

In their seminal treatise, Campbell and Stanley (1963) and later, Campbell and Cook (1979) and Shadish, Cook, and Campbell (2002) advocated the use of what they labeled quasi-experimental designs in situations in which complete pre-experimental equivalence between groups could not be accomplished through randomization. One specific design that results in studies high in internal validity is the non-equivalent control group design in which there are pre-tests and post-tests assessing the dependent variable(s) in two or more groups. This design was chosen for the present study. A convergent mixed methods design was used in which both quantitative and qualitative data were collected before, during, and after the intervention (Creswell \& Creswell, 2018). The quantitative results will be presented in this paper while qualitative results that contextualize these findings reported here will be presented in a companion manuscript. The independent variable was the type of teaching method employed by the course instructor - DI or IBL. The dependent variables were the students' math anxiety level as measured by the Mathematics Anxiety Rating Scale Short Version (MARS-S), their self-reported mathematics anxiety from journal entries, their achievement as measured by a test of their mathematics content knowledge, and their selfreported level of understanding from journal entries.

\section{Research Questions}

1. What effect do different teaching methods have on preservice teachers' levels of mathematics anxiety?

2. What effect do different teaching methods have on preservice teachers' mathematics achievement?

\section{Methods}

\section{Participants}

Participants $(n=103)$ were undergraduate students majoring in education enrolled in one of four sections of a mathematics content course for preservice teachers at a midsize, state-supported university in the Southeast United States. The course covers content relating to fractions, decimals, probability, and data analysis and is the second course in a three-course sequence. Approximately $96 \%$ of the participants were female, $2 \%$ freshmen, $36 \%$ sophomores, $53 \%$ juniors, and $9 \%$ seniors. The large percentage of female participants can be attributed to the disproportionate amount of female elementary education majors (95\%) at the university. Each of the participants was majoring in elementary education with a concentration in grades PK-3, grades 1-5, or grades 4-8. To preserve their anonymity throughout the study, all participants identified themselves with a randomly-generated 6-digit course ID number that they used on all instruments in place of their name.

\section{Data Collection Instruments}

Mathematics Anxiety: In all classes, the participants completed an initial demographic questionnaire. Participants' levels of mathematics anxiety were assessed using the Math Anxiety Rating Scale Short Version (MARS-S) pre- and post-intervention as well as through self-reports in journal entries throughout the semester. The MARS-S is a 30-item self-rating scale created by Richard Suinn (2003) that uses a 5point rating scale for each of the 30 items with a score of 1 indicating that the respondent is not at all frightened by that situation and a score of 5 indicating that the respondent is very much frightened by that situation. Overall anxiety scores are determined by 
adding the respondents' raw scores on each item with higher total scores indicating relatively higher levels of anxiety. According to Suinn (2003), the MARS-S has a test-retest reliability coefficient of $0.90(p<.001)$ at one-week intervals. In addition, Cronbach's alpha was found to be 96 , which confirms the instrument has high internal reliability indicating that the items are considered to be measuring the different dimensions of the same construct, mathematics anxiety. The MARS-S also has demonstrated construct and content validity. Specifically, correlations between the MARS-S and the longer 98item MARS were found to be $r=.92(p<.001)$ and $r$ $=.94(p<.001)$ when the instruments were administered one week apart to the same sample. Furthermore, Suinn (1993) found MARS-S scores to be negatively correlated with mathematics grades $r=$ $-.41(p<.001)$, which is not surprising because mathematics anxiety is known to be negatively associated with mathematics performance. Exploratory factor analysis of MARS-S data indicated that there are two primary factors: (a) learning mathematics anxiety and (b) mathematics evaluation anxiety (Suinn, 2003).

Content Knowledge: To assess participants' content knowledge and measure their achievement over the course of the semester, the participants completed a 20-question multiple-choice content knowledge assessment at two points in the semester. The participants completed the assessment during the first week of classes and then again at the end of the semester. Because the content knowledge assessment was administered at the end of the semester, the researcher opted to have it be a component of the final exam. This course, along with the other two courses in the sequence, have a common, departmental final exam that all enrolled students complete. The format of these exams is the same for the three courses and includes a multiple-choice component and a constructed-response component. The assessment was designed to align with course content while assessing students on both conceptual understanding and procedural fluency of selected course topics. Two mathematics instructors at the university who regularly taught the course reviewed the assessment and confirmed that the content was valid for the course.

Journal Entries: Teacher candidates at the university are assessed on their professional dispositions several times throughout their program. One disposition on which they are evaluated is their ability to be a self-reflective practitioner. Thus, participants completed five journal entries over the course of the semester in which they reflected upon their experiences, understanding of course material, and anxieties. In each journal entry, participants rated their understanding of course material and level of math anxiety each on a scale from 1 to 10 . A score of one indicated a low level of understanding (or math anxiety), whereas a score of 10 indicated a high level of understanding (or mathematics anxiety). They also detailed reasons for each self-assessed rating and documented any course content with which they needed additional practice.

\section{Course Format}

Sections: There were four sections of the class offered with enrollment totals in each class of $30,28,32$, and 13 students. Two of the four sections were taught using DI, and the other two sections were taught using IBL. The sections were all taught by the same course 
instructor, who also happened to be the lead researcher in this study. The instructor previously taught this course for several years in addition to having experience using both IBL and DI teaching methods in a variety of mathematics courses.

IBL: The format of the IBL classes consisted of students' collaborating with each other and presenting their solutions to problems from the course problem set. Small group work and communication with peers were emphasized during this time. Because the focus in the IBL classes was for the students to develop deep conceptual understanding as well as effective classroom communication and problem-solving skills, the instructor did not conduct any lectures. This was to minimize the likelihood of students' modeling the instructor's work, thus promoting independence in the students' thinking. A typical class meeting consisted of students' presenting their work from the previous class and participating in student-led discussions facilitated by the instructor regarding relevant course content, transitioning into small-group work on the next section of course material.

DI: The classes that were taught using DI were teacher-centered classes with the majority of class time spent on the instructor's lectures. Homework problems were briefly reviewed at the beginning of each class, and there was little time allocated for independent problem solving and communication among the students. The basis of the instructor's lectures and the assigned homework problems were from the same course problem set. Thus, the students in the IBL and DI classes completed the same problems over the course of the semester although the manner in which those problems were presented differed.

\section{Results}

\section{Demographics}

Demographic data included the participants' GPAs, college majors, grades in the previous mathematics course, and whether they had previously taken any IBL classes. It is noted that there were differences in GPA between the IBL and DI groups; however, there were no statistically significant differences in terms of scores on the pretest. Table 1 summarizes the demographic data.

\section{MARS-S}

A 2 (Teaching Method: IBL and DI) x 2 (Time: Initial and Final) mixed ANOVA revealed a statistically significant interaction between the teaching method and time on the MARS-S scores, $F(1,95)=11.91, p=$ .001 , partial $\eta^{2}=.111$. To test for simple effect of teaching method, independent samples $t$-tests were run to determine if there were differences in the initial and final MARS-S scores of the students in the IBL and DI classes. Initial MARS-S scores for the IBL students $(M=85.00, S D=17.71)$ were significantly higher than the scores for the DI students $(M=76.17, S D=21.19)$, $t(99)=2.22, p=.029, d=0.45$. However, the MARS$\mathrm{S}$ scores of the IBL students decreased while the MARS-S scores of the DI student increased over the course of the semester such that on the final MARS-S measure, there was not a statistically significant difference between the IBL $(M=79.84, S D=18.50)$ and DI students $(M=81.95, S D=18.67), t(97)=.56$, $p=.577, d=0.11$. Figure 1 displays the interaction. 


\section{Table 1}

Demographic Data

\begin{tabular}{|c|c|c|c|c|}
\hline \multirow[t]{2}{*}{ Characteristic } & \multicolumn{2}{|c|}{ IBL } & \multicolumn{2}{|c|}{ DI } \\
\hline & Frequency & Percentage & Frequency & Percentage \\
\hline \multicolumn{5}{|l|}{ Major } \\
\hline Grades PreK-3 & 15 & $34.1 \%$ & 16 & $28.0 \%$ \\
\hline Grades 1-5 & 21 & $47.7 \%$ & 34 & $59.6 \%$ \\
\hline Grades 4-8 & 8 & $18.2 \%$ & 7 & $12.3 \%$ \\
\hline \multicolumn{5}{|l|}{ GPA } \\
\hline$\geq 2.00$ & 2 & $4.5 \%$ & 1 & $1.7 \%$ \\
\hline $2.01-3.00$ & 26 & $59.1 \%$ & 25 & $43.1 \%$ \\
\hline $3.01-4.00$ & 16 & $36.4 \%$ & 32 & $55.2 \%$ \\
\hline \multicolumn{5}{|c|}{ Previous Course Grade } \\
\hline A & 5 & $11.4 \%$ & 22 & $38.6 \%$ \\
\hline B & 30 & $68.2 \%$ & 21 & $36.8 \%$ \\
\hline $\mathrm{C}$ & 9 & $20.5 \%$ & 14 & $24.6 \%$ \\
\hline \multicolumn{5}{|c|}{ Previous IBL Classes } \\
\hline Yes & 15 & $34.1 \%$ & 32 & $56.1 \%$ \\
\hline No & 29 & $65.9 \%$ & 25 & $43.9 \%$ \\
\hline
\end{tabular}

\section{Figure 1}

Mean MARS-S scores for the IBL and DI groups at the beginning and end of the semester.

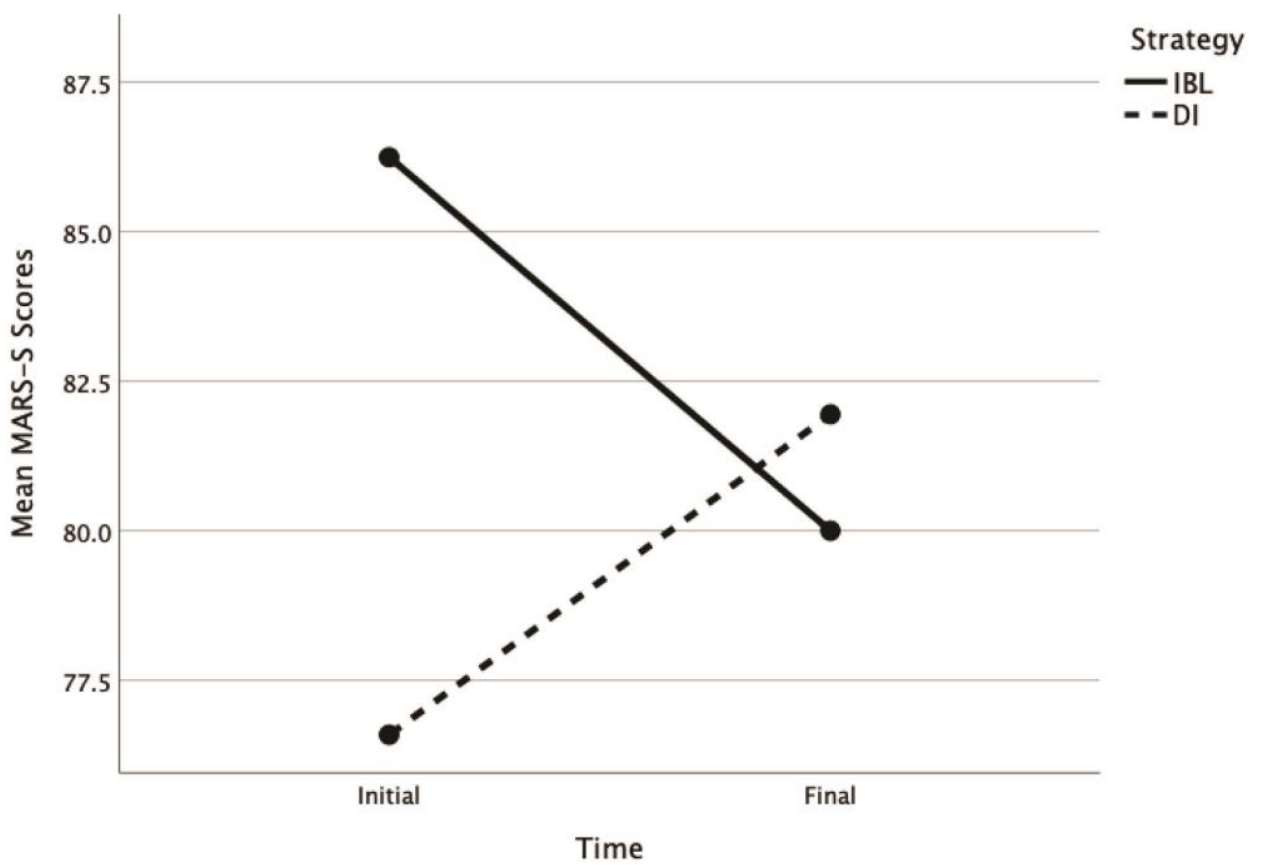


Paired samples $t$-tests were run to test for the simple effect of time. The IBL classes showed a statistically significant difference in initial and final MARS-S scores with final MARS-S scores $(M=80.00, S D=$ 18.90) being lower than initial MARS-S scores $(M=$ $86.24, S D=17.18), t(40)=2.41, p=.021, d=0.38$. The DI classes also had a statistically significant difference in initial and final MARS-S scores. However, in this case, final MARS-S scores $(M=$ $81.95, S D=18.67)$ were higher than initial MARS-S scores $(M=76.59, S D=21.19), t(55)=-2.48, p=$ $.016, d=0.33$. Table 2 summarizes descriptive statistics related to these measures.

\section{Table 2}

Initial and Final MARS-S Scores for Paired Samples t-Test

\begin{tabular}{llllllll}
\hline \multirow{2}{*}{ MARS-S Scores } & \multicolumn{3}{c}{$\mathrm{IBL}^{\dagger}$} & & \multicolumn{3}{c}{$\mathrm{DI}^{\dagger}$} \\
\cline { 2 - 4 } \cline { 7 - 8 } & $n$ & Mean & SD & & $n$ & Mean & SD \\
\hline Initial & 41 & 86.24 & 17.18 & & 56 & 76.59 & 21.19 \\
Final & 41 & 80.00 & 18.90 & & 56 & 81.95 & 18.67 \\
\hline
\end{tabular}

Note. ${ }^{\dagger}$ indicates a statistically significant difference within teaching methods.

\section{Self-reported Mathematics Anxiety}

A 2 (Teaching Method: IBL and DI) x 5 (Time: Journal 1, Journal 2, Journal 3 Journal 4, Journal 5) mixed ANOVA showed that there was a statistically significant interaction between the teaching method and self-reported mathematics anxiety scores over the course of the semester on the, $F(4,328)=7.57, p<$ .001 , partial $\eta^{2}=.085$. (See Figure 2).

When testing for the simple effect of time within each teaching method, Mauchly's test of sphericity indicated that the assumption of sphericity had been violated, $\chi^{2}(9)=19.33, p=.023$. Therefore, degrees of freedom were corrected using Greenhouse-Geisser estimates of sphericity $(\varepsilon=.78)$. Statistically significant differences in self-reported mathematics anxiety for the IBL classes over the course of the semester were found, $F(3.12,118.49)=6.14, p=.001$, partial $\eta^{2}=.139$. Pairwise comparisons showed that self-reported math anxiety was significantly reduced between journal entry $1(M=7.00, S D=2.44)$ and journal entry $5(M=5.59, S D=2.51), 95 \%$ CI $[0.018$, 2.803], $p=.045$. Significant differences in the selfreported math anxiety for the IBL group also existed between journal entry $2(M=7.31, S D=1.98)$ and journal entry $5(M=5.59, S D=2.51), 95 \%$ CI [0.451, 2.985], $p=.003$. There were also statistically significant differences in self-reported mathematics anxiety for the DI classes, $F(4,176)=3.47, p=.009$, partial $\eta^{2}=.073$. Pairwise comparisons for the DI classes indicated that self-reported mathematics anxiety increased to a statistically significant extent between journal entry $1(M=5.42, S D=2.55)$ and journal entry $5(M=6.78, S D=2.72), 95 \% \mathrm{CI}[-$ 2.616, -0.095$], p=.027$. There was also a significant increase between journal entry $3(M=5.62$, $S D=2.41)$ and journal entry $5(M=6.78, S D=2.72)$, $95 \%$ CI $[-2.167,-0.144], p=.015$. A significant increase also existed between journal entry $4(M=$ $5.58, S D=2.65)$ and journal entry $5(M=6.78, S D=$ $2.72), 95 \%$ CI [ $-2.298,-0.102], p=.023$. 


\section{Figure 2}

Mean self-reported math anxiety levels for the IBL and DI groups throughout the semester based on student journal entries.

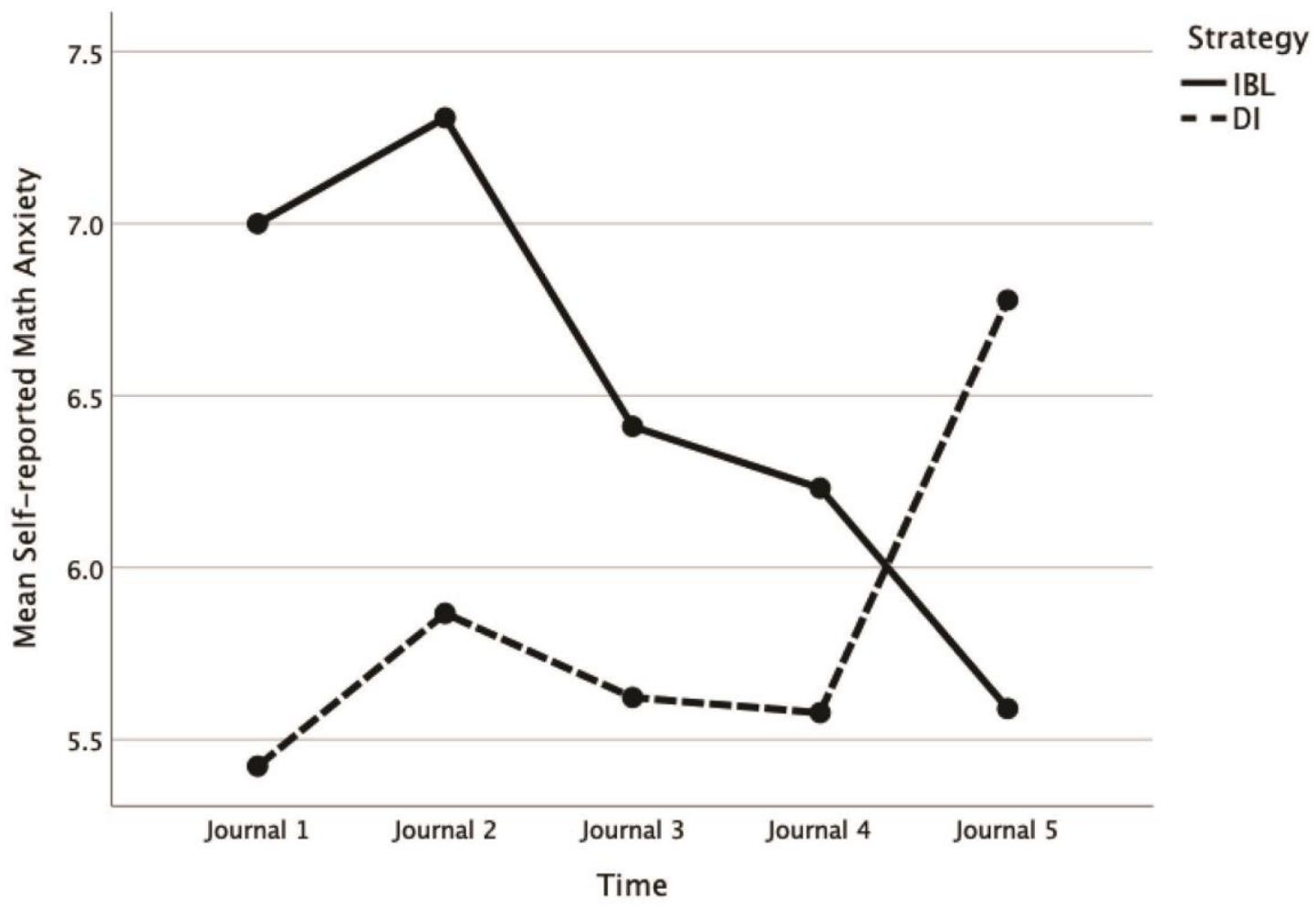

To test for the simple effect of teaching method on self-reported mathematics anxiety, independent samples $t$-tests were conducted for each time period. Significant differences were found between the classes for journal entry $1, t(94)=3.03, p=.003, d=0.62$; journal entry $2, t(96)=2.44, p=.017, d=0.51$; and journal entry $5, t(96)=-2.33, p=.022, d=0.47$. Corroborating the results of the MARS-S, the means for self-reported mathematics anxiety scores were higher for the IBL classes than the DI classes for journal entries 1 and 2 at the beginning of the semester but were lower for journal entry 5, which was submitted during the last week of classes. However, when applying the Bonferroni correction to control the family-wise error rate, the only remaining significant difference between the IBL and DI groups was for Journal 1. Descriptive statistics related to these measures are depicted in Table 3. 
Table 3

Self-reported Math Anxiety (MA) for Independent Samples t-Test

\begin{tabular}{llllllll}
\hline MA Journal & \multicolumn{3}{c}{ IBL } & & \multicolumn{3}{c}{ DI } \\
\cline { 2 - 3 } \cline { 7 - 8 } & $n$ & Mean & SD & & & Mean & SD \\
\hline Journal 1* & 43 & 6.93 & 2.40 & & 53 & 5.38 & 2.57 \\
Journal 2* & 42 & 7.12 & 2.05 & & 56 & 5.91 & 2.68 \\
Journal 3 & 44 & 6.39 & 2.21 & & 56 & 5.86 & 2.40 \\
Journal 4 & 44 & 6.20 & 2.46 & & 54 & 5.65 & 2.45 \\
Journal 5* & 44 & 5.73 & 2.46 & & 54 & 6.93 & 2.60 \\
\hline
\end{tabular}

Note. * indicates a statistically significant difference between teaching methods.

\section{Content Knowledge Assessment}

A 2 (Teaching Method: IBL and DI) x 2 (Time: Initial and Final) mixed ANOVA revealed that there was not a statistically significant interaction between the teaching method employed and measures of content mastery over the course of the semester on the content knowledge scores, $F(1,99)=0.75, p=.389$, partial $\eta^{2}=.008$. However, there was a statistically significant main effect of teaching method between the pre-test and post-test scores on the content knowledge assessment, $F(1,99)=212.92, p<.001$, partial $\eta^{2}=$ .683. Based on the results of paired samples $t$-tests, there were statistically significant differences between the initial and final scores for the IBL classes, $M=$ $-4.41,95 \%$ CI $[-5.28,-3.54], t(43)=-10.24, p<$ $.001, d=1.54$, as well as for the traditional classes, $M$ $=-4.97,95 \%$ CI $[-5.88,-4.05], t(56)=-10.89, p<$ $.001, d=1.44$. Thus, both teaching methods resulted in statistically significant increases in content mastery over the course of the semester with no statistically significant difference between the two. Figure 3 displays the mean content knowledge scores.

\section{Self-reported Understanding}

A two-way 2 (Teaching Method: IBL and DI) x 4 (Time: Journal 2, Journal 3, Journal 4, Journal 5) mixed ANOVA showed that there was not a statistically significant interaction between the teaching method and the time elapsed over the course of the semester on the self-reported level of understanding, $F(3,222)=1.07, p=.363$, partial $\eta^{2}$ $=.014$. However, there was a statistically significant main effect of teaching method between the journal entries, $F(3,222)=3.87, p=.010$, partial $\eta^{2}=.050$. There was a statistically significant increase in selfreported understanding from journal $2(M=5.62, S D$ $=2.23)$ to journal $3(M=6.54, S D=2.08), 95 \% \mathrm{CI}$ $[-1.52,-0.34], p=.002$. A significant increase was also found between journal $2(M=5.62, S D=2.23)$ and journal $4(M=6.21, S D=1.96), 95 \% \mathrm{CI}$ $[-1.24,-0.03], p=.040$. There was a statistically significant increase in self-reported understanding from journal $2(M=5.62, S D=2.23)$ to journal $5(M$ $=6.22, S D=2.30), 95 \%$ CI $[-1.24,-0.14], p=.014$. Figure 4 displays the mean self-reported levels of understanding. Because journal entry 1 was collected on the second day of class, students were not asked to discuss their level of understanding of course material in their journal entries, only their mathematics anxiety. 


\section{Figure 3}

Mean content knowledge scores for the IBL and DI groups on pre- and post-assessments.

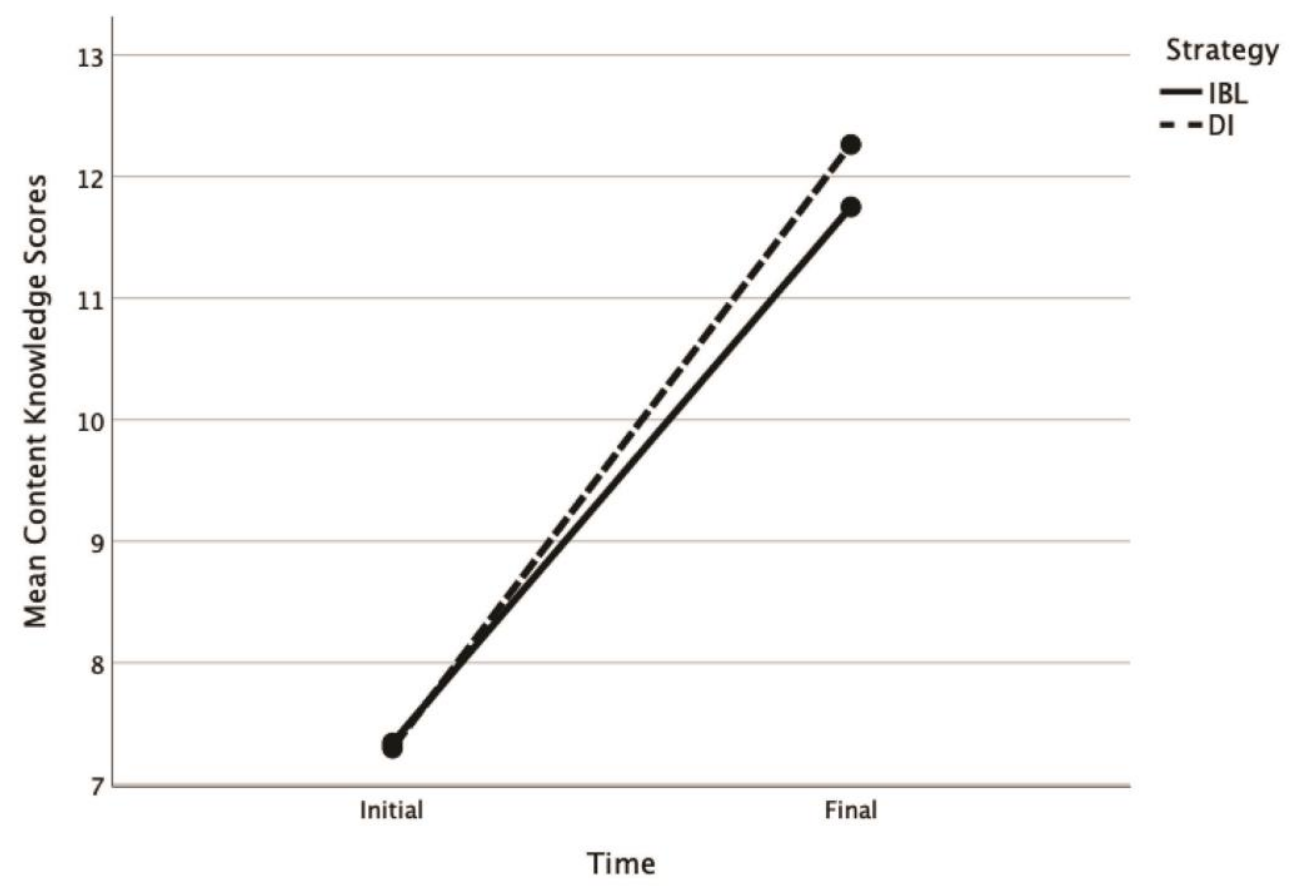

Figure 4

Mean self-reported levels of understanding for IBL and DI groups throughout the semester based on student journal entries.

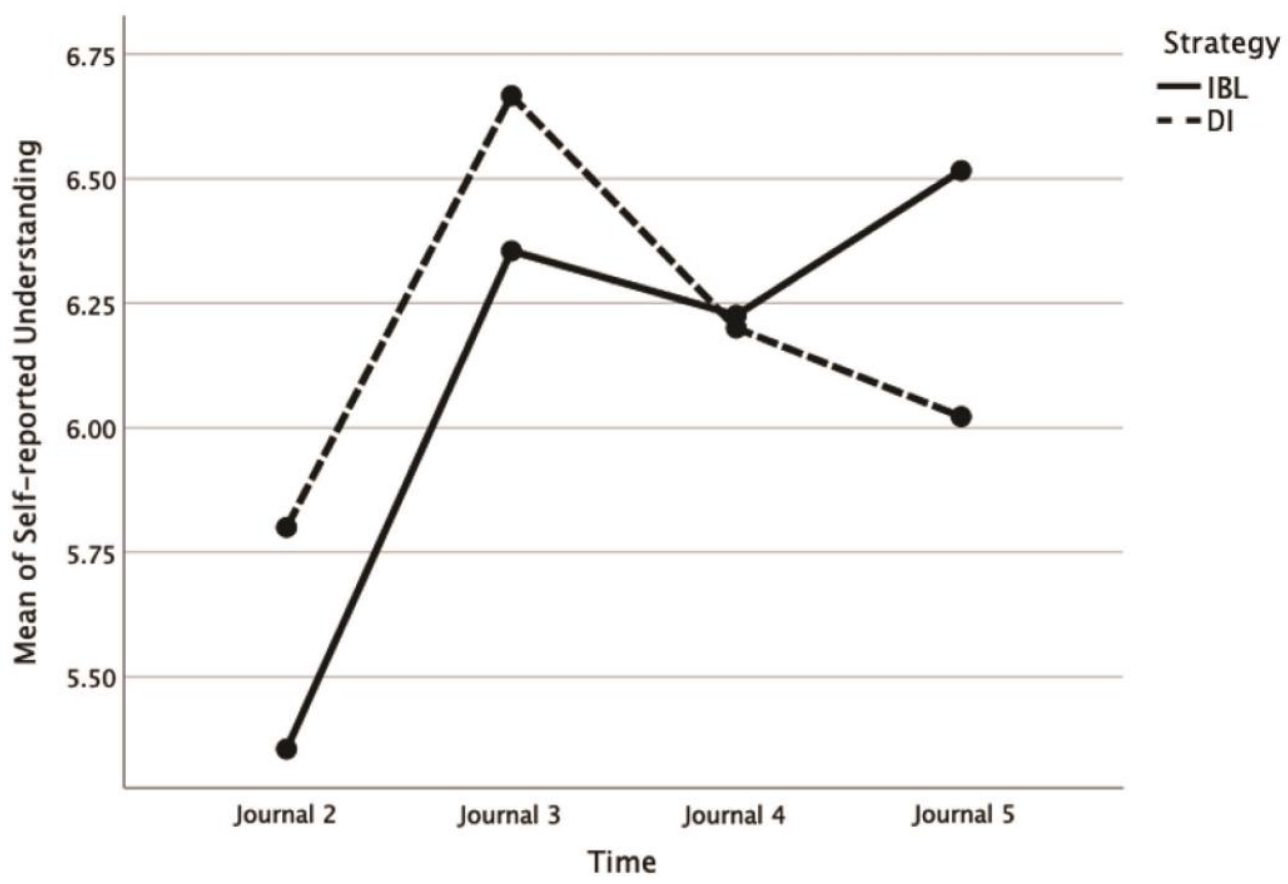




\section{Correlational Analysis}

Pearson's correlation coefficient was computed between students' self-reported levels of mathematics anxiety and understanding, as well as initial and final MARS-S and content knowledge scores. Notable correlations include the statistically significant negative relationship between each self-reported level of mathematics anxiety with its corresponding selfreported level of understanding, indicating that as mathematics anxiety scores increased, students' levels of understanding decreased (journal entry 2: $r(93)=$ $-.52, p<.01$; journal entry $3: r(92)=-.40, p<.01$; journal entry $4: r(86)=-.56, p<.01$; journal entry 5 : $r(89)=-.37, p<.01)$. There was also a strong positive correlation between students' initial and final MARS-S scores, $r(95)=.61, p<.01$, whereas a weak negative correlation existed between students' final MARS-S scores and final content knowledge scores, $r(97)=-.28, p<.01$. A significant strong positive correlation existed between students' initial MARS-S scores and their self-reported level of mathematics anxiety at the beginning of the semester on journal entry $1, r(92)=.65, p<.01$. Final MARS-S scores and the students' self-reported level of mathematics anxiety at the end of the semester on journal entry 5 were moderately positively correlated, $r(94)=.49, p<$ .01. The results are summarized in Table 4. The interpretations of these correlations were based on benchmarks provided by Cohen (1988).

\section{Table 4}

Correlations

\begin{tabular}{|c|c|c|c|c|c|c|c|c|c|c|c|c|}
\hline Measure & 1 & 2 & 3 & 4 & 5 & 6 & 7 & 8 & 9 & 10 & 11 & 12 \\
\hline \multicolumn{13}{|l|}{ 1. IN.MARS } \\
\hline 2. FI.MARS & $.61 * *$ & & & & & & & & & & & \\
\hline 3. IN.CK & -.14 & $-.26^{* *}$ & & & & & & & & & & \\
\hline 4. FI.CK & $-.25^{*}$ & $-.28 * *$ & $.24^{*}$ & & & & & & & & & \\
\hline 5. J1MA & $.65 * *$ & $.33 * *$ & -.11 & -.18 & & & & & & & & \\
\hline 6. J2MA & $.50 * *$ & $.41 * *$ & -.13 & $-.29 * *$ & $.49 * *$ & & & & & & & \\
\hline 7. J3MA & $.42 * *$ & $.43 * *$ & $-.25^{*}$ & $-.40 * *$ & $.45^{* *}$ & $.34 * *$ & & & & & & \\
\hline 8. J4MA & $.49 * *$ & $.48 * *$ & $-.29 * *$ & $-.49 * *$ & $.45^{* *}$ & $.43 * *$ & $.58 * *$ & & & & & \\
\hline 9. J5MA & .19 & $.49 * *$ & $-.25 *$ & $-.42 * *$ & $.28 * *$ & $.32 * *$ & $.56 * *$ & $.57 * *$ & & & & \\
\hline 10. J2UN & $-.24 *$ & $-.34 * *$ & .08 & $.33 * *$ & -.16 & $-.52 * *$ & -.20 & -.17 & $-.25 *$ & & & \\
\hline 11. J3UN & $-.33 * *$ & $-.43 * *$ & .14 & $.24^{*}$ & -.19 & -.14 & $-.40^{* *}$ & $-.28 * *$ & $-.33 * *$ & $.32 * *$ & & \\
\hline 12. J4UN & $-.37 * *$ & $-.46^{* *}$ & $.37 * *$ & $.40 * *$ & $-.25 *$ & -.16 & $-.38 * *$ & $-.56 * *$ & $-.48 * *$ & $.26^{*}$ & $.51 * *$ & \\
\hline 13. J5UN & -.10 & -.21 & -.02 & .21 & -.08 & -.18 & -.15 & $-.21 *$ & $-.37 * *$ & $.41 * *$ & $.32 * *$ & $.30 * *$ \\
\hline
\end{tabular}

Note. IN.MARS = initial MARS-S score, FI.MARS = final MARS-S score, IN.CK = initial content knowledge score, FI.CK = final content knowledge score, JIMA = journal 1 mathematics anxiety level, J2MA = journal 2 mathematics anxiety level, J3MA = journal 3 mathematics anxiety level, J4MA = journal 4 mathematics anxiety level, J5MA = journal 5 mathematics anxiety level, J2UN = journal 2 understanding level, J3UN = journal 3 understanding level, J4UN = journal 4 understanding level, J5UN = journal 5 understanding level. *p $<.05 . * * p<$ .01 


\section{Discussion}

Although previous research has demonstrated that the implementation of inquiry-based Learning (IBL) in college-level STEM courses successfully promotes content mastery (e.g. Freeman et al., 2014; Kogan \& Laursen, 2013; Laursen \& Hassi, 2012; Smith et al., 2009), no study had previously included a direct comparison of IBL methods with more traditional pedagogical practices. This is the first known study to use a quasi-experimental design, the non-equivalent control group design, as part of a mixed methods investigation to assess the direct effects of teaching method on preservice students' math anxiety and achievement. The primary advantage of the use of this design feature is that it provides a high degree of internal validity thereby allowing for a high degree of confidence in the inference of cause-effect relationships not possible with other types of methodologies (Campbell \& Stanley, 1963; Cook \& Campbell; 1979; Shadish, et al., 2002).

The results of the present study show statistically significant gains in content knowledge from pretest to posttest over the course of the semester for both groups with no statistically significant differences between these two different teaching methods. These results differ from those reported in the meta-analysis performed by Freeman et al. (2014), which indicated that students enrolled in active-learning classes in STEM disciplines experienced higher achievement scores than those enrolled in traditional classes. Perhaps, as this study indicates, student achievement may be affected by other variables, such as the course instructor or course materials, rather than the teaching methods employed by the instructor. It is worth noting that while both groups demonstrated improved content knowledge, the degree to which they did is somewhat disappointing. On the 20-question assessment, both groups improved their average number correct from approximately 7 questions at the beginning of the semester to approximately 12 questions at the end of the semester. While this result may be statistically significant in terms of achievement, it does indicate an overall lack of sufficient content knowledge related to the course content that warrants further investigation.

Because of the quasi-experimental design of the study, the findings strongly suggest that trajectories of anxiety over the course of the semester are causally related to the teaching method used in the course. Analyses revealed a significant difference between the IBL and DI groups in their initial mathematics anxiety based on both the MARS-S scores and self-reported levels of mathematics anxiety from the students' journal entries. At the beginning of the semester, the IBL group reported significantly higher mathematics anxiety than did the DI group on both measures. As the semester progressed, the trajectory of mathematics anxiety for both groups flowed in different directions. By the end of the semester, mathematics anxiety had significantly decreased for the IBL group on both measures. In contrast, however, mathematics anxiety significantly increased for the DI group on both measures. It is important to note that on the MARS-S, the final mathematics anxiety levels between the IBL and DI groups were not significantly different from each other, whereas the self-reported mathematics anxiety levels of the IBL group were significantly lower than the DI group on the final journal entries. These results differ from those of Alsup (2004) who found that students enrolled in a DI, lecture-style course showed a larger decline in mathematics anxiety as compared to those in a constructivist, activelearning course. On the other hand, the results are 
consistent with those of Pan and Tang (2005), Harper and Daane (1998) and Sloan (2010) who found that features of IBL classes, such as emphasis on problem solving, small group work, peer teaching, and actively participating in class, are helpful in reducing mathematics anxiety.

The results on the students' self-reported mathematics anxiety are not at all surprising. For approximately two-thirds of the IBL participants, this was their first time in an IBL class. Being told on the first day of class that there would be no class lectures and that the students would do the majority of the work on the boards could have come as a shock to many of the students and could have been a contributing factor to their heightened anxiety levels. Furthermore, both groups demonstrated increased anxiety levels between the first and second journals; however, this can possibly be attributed to several factors. These include the first unit in the course focusing on fractions (a topic that is historically challenging for the teacher candidates), the first test in the class being administered near the time Journal 2 was submitted, and in the case of the IBL students, becoming accustomed to the new course format. However, once the IBL students had sufficient time in the course to become familiar with the format, their anxiety began to decrease and continued to do so for the remainder of the semester, even as the final exam approached. The same cannot be said for the DI students. Whereas their anxiety levels remained fairly constant and lower than the IBL students throughout the majority of the semester, their anxiety peaked and surpassed that of the IBL students before the final exam.

Mathematics anxiety is well-known to have a detrimental effect on student learning outcomes (e.g.
Hembree, 1990). Consistent with previous findings, significant negative correlations between mathematics anxiety and content knowledge were found, implying that as students' math anxiety increased, their achievement decreased. Indeed, and not unexpectedly, there were several converging lines of evidence in the data for an inverse relationship between mathematics anxiety and mathematics achievement. Overall and irrespective of teaching method, correlational analysis yielded significant negative relationships between participants' selfreported levels of mathematics anxiety and selfreported levels of understanding as indicated in the journal entries. For those participants' whose selfreported level of anxiety increased over the course of the semester, self-reported levels of understanding decreased while for those for whom anxiety levels decreased, their self-reported levels of content mastery increased. Corroborating these findings in the present study was the presence of a weak negative correlation between participants' final MARS-S scores and final content knowledge scores at the end of the semester. These results are consistent with the results of prior studies including those of Hembree's (1990) metaanalysis of data from 225 research studies, which indicated a significant negative correlation between mathematics anxiety and achievement as well as those of Ashcraft and Kirk (2001).

\section{Conclusion}

The preservice teachers who were enrolled in the courses with IBL as the teaching method experienced a significant decrease in their levels of mathematics anxiety over the course of the semester as compared to the preservice teachers who were enrolled in the courses with DI as the teaching method as evinced by both the MARS-S scores and participants' selfreported mathematics anxiety levels. However, while 
each group of participants experienced significant increases in achievement based on the results of content-specific pre- and post-test gains, there was not a statistically significant difference in achievement between the IBL and DI participants. Finally, corroborating previous research, the present study found a negative relationship between mathematics anxiety and student learning outcomes.

\section{Limitations}

The study was limited to only preservice elementary school teachers who self-enrolled in the researcher's mathematics content course based on their scheduling needs. Student assignments to class sections were not random. The results of the study may not generalize to students with other college majors or those enrolled in other mathematics courses. The study was also limited to primarily female students. Approximately $96 \%$ of the participants were female, so the results of the study may not generalize to classes in which the majority of the students are not female. Additionally, the study was limited by its short time frame as it was conducted over a single semester, and the course in which the participants were enrolled is the second course in a three-course sequence. Lastly, the study was limited by the honesty and clarity of the participants' responses on questionnaires and journal entries.

\section{Impact at Institution}

The results of this study have already made a direct impact on the design of mathematics coursework required for teacher certification at the institution at which it was conducted. New courses for pre-service teachers have been designed to accommodate updated state guidelines, and the course materials that have been recently adopted promote discovery learning and collaboration among students. Furthermore, instructors of these courses now incorporate inquiry, problem solving, and reflection regularly during class meetings.

\section{Recommendations for Practice}

Based on the results of this study, it is recommended that instructors of mathematics content courses for preservice elementary teachers strongly consider adopting student-centered, IBL techniques in their classrooms. Furthermore, it is recommended that they familiarize themselves with current standards, including Common Core Standards for Mathematical Practice, NCTM Effective Teaching Practices, and AMTE Standards for Preparing Teachers of Mathematics. Participating in professional development opportunities focused on studentcentered learning and conceptual understanding of mathematics could also prove to be helpful.

\section{Recommendations for Future Research}

Further research is needed to determine if the results from this study would generalize to students with different college majors or to those enrolled in general education mathematics courses. Also, a longitudinal study following a cohort of preservice elementary teachers through the entire elementary education sequence of mathematics content courses taught using IBL methods could offer invaluable insight into their experiences and the impact of those experiences on their own teaching methods. 


\section{References}

Alsup, J. (2004). A comparison of constructivist and traditional instruction in mathematics. Educational Research Quarterly, 28(4), 3-17.

Althauser, K. (2018). The emphasis of inquiry instructional strategies: Impact on preservice teacheres' mathematics efficacy. Journal of Education and Learning, 7(1), 53-70.

Ardeleanu, R. (2019). Traditional and modern teaching methods in mathematics. Journal of Innovation in Psychology, Education, and Didactics, 23(2), 133-140.

Ashcraft, M.H. (1995). Cognitive psychology and simple arithmetic: A review and summary of new directions. Mathematical Cognition, 1, 3-34.

Ashcraft, M.H. \& Kirk, E.P. (2001). The relationship among working memory, math anxiety, and performance. Journal of Experimental Psychology, 130(2), 224-237.

Association of Mathematics Teacher Educators. (2017). Standards for preparing teachers of mathematics. Retrieved from amte.net/standards

Bandura, A. (1977). Social learning theory. Englewood Cliffs, NJ: Prentice Hall.

Boaler, J. (2008). What's math got to do with it? New York, NY: Viking Penguin.

Brahier, D.J. (2013). Teaching secondary and middle school mathematics ( $4^{\text {th }}$ ed.). Boston, MA: Pearson

Buhlman, B.J. \& Young, D.M. (1982). On the transmission of mathematics anxiety. Arithmetic Teacher, 30(3), $55-56$.

Burns, M. (1998). Math: Facing an American phobia. Sausalito, CA: Math Solutions Publications.

Bursal, M. \& Paznokas, L. (2006). Mathematics anxiety and preservice elementary teachers' confidence to teach mathematics and science. School Science and Mathematics, 106(4), 173-180.

Campbell, D.T., Stanley, J.C., \& Gage, N.L. (1963). Experimental and quasi-experimental designs for research. Boston, MA: Houghton Mifflin.

Cemen, P.B. (1987). The nature of mathematics anxiety. (Report No. SE 048 689). Stillwater, OK: Oklahoma State University. (ERIC Document Reproduction Service No. ED 287 729).

Cohen, J. (1988). Statistical power analysis for the behavioral sciences $\left(2^{\text {nd }}\right.$ ed.). Lawrence Erlbaum.

Conference Board of the Mathematical Sciences. (2012). The mathematical education of teachers II. Providence, RI. and Washington, DC: American Mathematical Society and Mathematical Association of America.

Cook, T.D. \& Campbell, D.T. (1979). Quasi- experimentation: Design and analysis issues for field settings. Chicago: Rand-McNally.

Creswell, J.W. \& Creswell, J.D. (2018). Research design: Qualitative, quantitative, and mixed methods approaches ( $5^{\text {th }}$ ed.). Thousand Oaks, CA: SAGE Publications, Inc.

de Jong, T. \& van Joolingen, W.R. (1998). Scientific discovery learning with computer simulations of conceptual domains. Review of Educational Research, 68(2), 179-201.

Dutton, W.H. \& Dutton, A. (1991). Mathematics children use and understand. Mountain View, CA: Mayfield.

Fetterly, J.M. (2020). Fostering mathematical creativity while impacting beliefs and anxiety in mathematics. Journal of Humanistic Mathematics, 10(2), 102-128. 
Freeman, S., Eddy, S.L., McDonough, M., Smith, M.K., Okoroafor, N., Jordt, H., \& Wenderoth, M.P. (2014). Active learning increases student performance in science, engineering, and mathematics. PNAS, 111(23), 8410-8415.

Harper, N.W. \& Daane, C.J. (1998). Causes and reduction of math anxiety in preservice elementary teachers. Action in Teacher Education, 19(4), 29-38.

Hembree, R. (1990). The nature, effects, and relief of mathematics anxiety. Journal for Research in Mathematics Education, 21(1), 33-46.

Karp, K.S. (1988). The teaching of elementary school mathematics: The relationship between how mathematics is taught and teacher attitudes. Dissertation Abstracts International, 49(08), 2138.

Karp, K.S. (1991). Elementary school teachers' attitudes toward mathematics: The impact on students' autonomous learning skills. School Science and Mathematics, 9(1), 265-270.

Kogan, M., \& Laursen, S. L. (2013). Assessing long-term effects of inquiry-based learning: A case study from college mathematics. Innovative Higher Education, 39(3), 183-199.

Laursen, S., \& Hassi, M.L. (2012). Outcomes of inquiry-based learning for pre-service teachers: A multi-site study. In (Eds.) S. Brown, S. Larsen, K. Marrongelle, and M. Oehrtman, Proceedings of the 15th Annual Conference on Research in Undergraduate Mathematics Education, p. 88-94, Portland, Oregon.

Lubinski, C.A. \& Otto, A.D. (2004). Preparing K-8 preservice teachers in a content course for standards-based mathematics pedagogy. School Science and Mathematics, 104(7), 336-350.

Mestre, J.P. \& Cocking, R.R. (2002). Applying the science of learning to the education of prospective science teachers. In R. Bybee (Ed), Learning Science and the Science of Learning (13-22). Arlington, VA: NSTA Press.

Middleton, J.A. \& Spanias, P.A. (1999). Motivation for achievement in mathematics: Findings, generalizations, and criticisms of the research. Journal for Research in Mathematics Education, 30, 65-88.

National Council of Teachers of Mathematics. (1991). Professional Standards for Teaching Mathematics. Reston, VA: NCTM.

Pan, W. \& Tang, M. (2005). Students' perceptions on factors of statistics anxiety and instructional strategies. Journal of Instructional Psychology, 32(3), 205-214.

Prince, M.J. \& Felder, R.M. (2006). Inductive teaching and learning methods: Definitions, comparisons, and research bases. Journal of Engineering Education, 95, 123-138.

Ramirez, G., Hooper, S., Kersting, N., Ferguson, R., \& Yaeger, D. (2018) Teacher math anxiety relates to adolescent students' math achievement. AERA Open, 4(1), 1-13.

Rhoads, M.A. (2020). A taxonomy of behaviors by instructors that college students identified as contributing to their math anxiety [ProQuest Information \& Learning]. In Dissertation Abstracts International: Section B: The Sciences and Engineering (Vol. 81, Issue 9-B).

Ronghuan, J., Liu, R., Star, J., Zhen, R., Wang, J., Hong, W., Jiang, S., Sun, Y., \& Fu, X. (2021). How mathematics anxiety affects students' inflexible perseverance in mathematics problem-solving: Examining the mediating role of cognitive reflection. British Journal of Educational Psychology, 91(1), 237-260. 
Rozgonjuk, D., Kraav, T., Mikkor, K., Roav-Puurand, K., \& That, K. (2020). Mathematics anxiety among STEM and social sciences students: The roles of mathematics self-efficacy, and deep surface approach to learning. International Journal of STEM Education, 7.

Schink, A.G. (2014). The road to present day inquiry-based learning. Retrieved from http://www.inquirybasedlearning.org/?page=Why_Use_IBL

Scholfield, H.L. (1981). Teacher effects on cognitive and affective pupil outcomes in elementary school mathematics. Journal of Educational Psychology, 73, 462-471.

Shadish, W.R., Cook, T.D., \& Campbell, D.T. (2002). Experimental and quasi-experimental designs for generalized causal inference. Boston, MA: Houghton Mifflin.

Sloan, T. (2010). A quantitative and qualitative study of math anxiety among preservice teachers. The Educational Forum, 74(3), 242-256.

Smith, T., Ware, D., Cochran, R., \& Shores, M. (2009). Mathematical investigations in inquiry-based courses for pre-service teachers. Retrieved from http://sigmaa.maa.org/rume/crume2009/Smith_LONG.pdf

Suinn, R.M. (2003). The mathematics anxiety rating scale, a brief version: Psychometric data. Psychological Reports, 92(1), 167-173.

Szczygiel, M. (2020). When does math anxiety in parents and teachers predict math anxiety and math achievement in elementary school children? The role of gender and grade year. Social Psychology of Education 23(4), 1023-1054.

Thanheiser, E., Browning, C.A., Moss, M., Watanabe, T., \& Garza-Kling, G. (2010). Developing mathematical content knowledge for teaching elementary school mathematics. Issues in the Undergraduate Preparation of School Teachers, 1, 1-13.

Trujillo, K.M. \& Hadfield, O.D. (1999). Tracing the roots of mathematics anxiety through in-depth interview with preservice elementary teachers. College Student Journal, 33(2), 219-232.

Wu, S.S., Willcutt, E.G., Escovar, E., \& Menon, V. (2014). Mathematics achievement and anxiety and their relation to internalizing and externalizing behaviors. Journal of Learning Disabilities, 47(6), 503-514. 


\section{Corresponding Author Contact Information:}

Author name: Janelle K. Lorenzen, Ph.D.

Department: Department of Mathematics

University, Country: Southeastern Louisiana University, Hammond, LA, USA

Email: Janelle.lorenzen@southeastern.edu

Please Cite: Lorenzen, J., K., \& Lipscomb, T., J. (2021). The Effects of Instructional Strategies on Preservice Teachers' Math Anxiety and Achievement. Journal of Research in Science, Mathematics and Technology Education, 4(2), 133-151. DOI: https://doi.org/10.31756/jrsmte.425

Copyright: () 2021 JRSMTE. This is an open-access article distributed under the terms of the Creative Commons Attribution License, which permits unrestricted use, distribution, and reproduction in any medium, provided the original author and source are credited. 